Bol. Acad. peru. leng. 61. 2016 (69-92)

\title{
Naturaleza, arte y amor en tres poemas largos de Javier Sologuren: Estancias (1960), Recinto (1967) y La hora (1980)
}

Nature, art and love in three long poems by Javier Sologuren: Estancias (1960), Recinto (Enclosure, 1967) and La hora (The hour, 1980

\section{DANiEl A. Romero SuÁreZ \\ Vanderbilt University}

Resumen:

Este trabajo analizará tres poemas largos escritos por Javier Sologuren: Estancias (1960), Recinto (1967) y La hora (1980), composiciones que tienen como eje la pregunta sobre el origen y las posibilidades del arte, entretejida con una reflexión sobre la naturaleza y el amor. Sin embargo, estos elementos no serán tratados con igual intensidad en los tres poemas mencionados. En Estancias, la reflexión sobre el arte se hará desde una perspectiva muy ligada a una naturaleza de ascendencia romántica, aunque será un amor arquetípico el que permitirá mayor trascendencia. Luego, Recinto utilizará imágenes de excavaciones en la tierra para mostrar cómo a través de la poesía se puede revitalizar el pasado y vencer la parálisis de la muerte. Finalmente, en La hora, el escenario será la ciudad moderna, con sus vicios y virtudes, en que el 
arte y el amor se esgrimirán como medios contrarios al «espectáculo de la muerte».

\section{Abstract:}

This paper will analyze three long poems written by Javier Sologuren: Estancias (1960), Recinto (Enclosure, 1967) and La hora (The hour, 1980). These compositions center on the origin and the possibilities of the art, interwoven with a reflection on the nature and love. However, these elements will not be treated with equal intensity in the three aforementioned poems. In Estancias, the reflection on art will be from a very romantic nature perspective, although it will be an archetypal love which will allow greater significance. Then, in Recinto, it will use images of land excavations to show how can it revitalize the past and overcome paralysis of death through poetry. Finally, in La hora, the scenario will be the modern city, as for its vices as for its virtues, where the art and the love are wielded as contrary means to the «spectacle of death».

Palabras clave: Amor, naturaleza, arte poética, tradición, muerte.

Keywords: Love, nature, poetic art, tradition, death.

Recibido: 31/03/2016

Aceptado: 28/04/2016 


\section{Sologuren y su descubrimiento de la naturaleza}

Ante la pregunta por cómo se inició en el oficio literario, Sologuren recuerda una experiencia de dolor y soledad que tuvo lugar en su infancia. Enfermo de paludismo, vivía en Barranco, distrito limeño, debido a que el clima era más favorable. En general, el pequeño Javier estaba aislado de relaciones humanas y, de esta situación, vendría su particular acercamiento a la naturaleza:

cuando me podían sacar al huerto de mi casa en Barranco enfrentaba mis primeros contactos con la vida exterior, que era la vida vegetal. Creo que de ahí viene mi inclinación por la naturaleza, una inclinación que nunca me abandona y que es constante en mi poesía. (2005: 403)

Entre otros rasgos, la poesía de Sologuren desarrollaría un tinte simbolista a partir de imágenes de la naturaleza. Y en este punto, cabe resaltar la gran semejanza con una de las experiencias de formación de sensibilidad de José María Eguren (1874-1942). La estadía de este poeta en las haciendas Chuquitanta y Pro se prolongó durante su niñez debido a su mala salud, que lo obligó a vivir en climas favorables, lo que generó «la fuerte y decisiva influencia de la naturaleza en esos años formativos en que la mente retiene todo con mayor intensidad y que se vio acrecentada, con seguridad, por la cuota de soledad que se le añadía» (Silva-Santisteban 2015: 8).

La cercanía con la naturaleza no fue para Sologuren solo un tema o tópico, sino que fue una experiencia íntima que lo llevó, como indicó él mismo, a desear «hacer míos a los demás seres y a mí mismo» 
(2005: 319). A partir de la naturaleza, entonces, se deseó no solo ser consciente y guiar la existencia de uno mismo, sino también ser parte de la totalidad que representan «los demás seres». Aquí estaría la semilla del simbolismo de su poesía que, al igual que el de Eguren, antes que al simbolismo europeo, se debe a una fascinación de alcance trascendente inspirada por una experiencia de gran proximidad a la naturaleza ocurrida durante la infancia.

Finalmente, es importante tener en cuenta que el padecimiento de su enfermedad, según cuenta el mismo poeta:

me llevó a expresarme, a liberarme de ese padecimiento, de ese confinamiento en un lecho, propio de la enfermedad crónica. Creo que ese origen vivencial de mi poesía se sigue manteniendo. Escribo poco y solamente cuando me siento atenaceado por problemas no estéticos, sino vitales, de mi propia existencia. (2005: 358)

De esta manera, la palabra se volvió no solo un medio de comunicación pragmático, sino también un medio para liberarse del padecimiento $y$, en ese sentido, fue una fuente de vitalidad frente a la contrariedad.

\section{Naturaleza y humanidad en Estancias}

Esta deuda con la naturaleza es clara en poemarios como El morador (1944), Diario de Perseo (1946-1948) o Dédalo dormido (1949). Por ejemplo, en este último poemario, la segunda estrofa del poema «La vista del mar» ${ }^{1}$ revela

1 Los poemas citados serán tomados de Vida continua (2004), primer tomo de las Obras completas de Javier Sologuren. 
que es la presencia del mar que, cual musa, permite la expresión de la voz poética: «Toda palabra es mía cuando estoy a la orilla / de tus ojos, mar, todo silencio es mío». Sin embargo, ya en el poemario Vida continua (1948-1950) puede vislumbrarse una nueva voz. Así, en «Árbol que eres un penoso relámpago...» el sujeto poético ya no requiere de ser poseído por un elemento de la naturaleza para ser dueño de la palabra, sino que se está forjando un elemento nuevo en el corazón, que permite, como indica la tercera estrofa, el canto en soledad. Incluso, ahora el cielo parece sofocar a la voz poética, quien anuncia un futuro en que la frente abandonará una «lámpara vacía» que cae de su frente. De este modo, el poema profetiza una renovación no solo del corazón, sino también del sistema de pensamiento de la cabeza a favor del canto en soledad.

Sin embargo, Vida continua no se debe tomar como un eje que separa dos estilos o concepciones poéticas radicalmente diferentes. Se trata, más bien, del anuncio de una nueva sensibilidad poética. Por ello, el imaginario de la naturaleza continúa muy presente en un poema posterior como Estancias. En este, mediante pequeños himnos de alabanza rituales, se logra una síntesis de una primera etapa de la poesía de Sologuren. A lo largo de las estancias poéticas, como a través de un sueño que abre las puertas a un universo poético, el yo dialoga con sus raíces y obsesiones poéticas. Los elementos naturales son los más evidentes, y muestran una mirada panteísta del cosmos. Comencemos citando el cuarto fragmento de Estancias: 
Giro, Mar, sobre tu aliento.

De ti salí, hacia ti vuelvo.

Soy tu fábula, tu espuma;

y tu anhelo, tu sueño

indescifrable

me palpita en la marea

de la sangre.

En este primer himno vemos cómo la voz poética sugiere no solo una relación de cercanía con el Mar, sino también de identidad. El Mar es el creador de la voz («soy tu fábula»), pero ha sido la misma fuente de agua quien ha dado parte de sí para generar al sujeto poético («[soy] tu espuma»). Por ello, el sujeto está estructurado como un mar: su sangre es una marea. Así, la persona se une a los ritmos infinitos del Mar desde su propia existencia carnal. Existe, por lo tanto, una correspondencia entre lo humano y la naturaleza.

Más adelante, en la novena estrofa, la naturaleza se erigirá como un lugar sagrado y de adoración. De manera precisa, el árbol se convierte en «altar»:
Árbol, altar de ramas, de pájaros, de hojas, de sombra rumorosa; en tu ofrenda callada, en tu sereno anhelo, hay soledad poblada de luz de tierra y cielo.

El árbol se muestra como un centro vital que une cielo y tierra, y muestra otro plano de la naturaleza: como merecedora de ofrendas. No obstante, la naturaleza no es solamente un lugar de adoración, sino que también 
produce palabras y musicalidad, de manera semejante al poeta; así, la correspondencia Naturaleza-Hombre también se da en el sentido inverso al que se mencionó anteriormente: ahora, la Naturaleza se asemeja a la Humanidad. Como se ve en el decimosexto fragmento, el Río, mientras avanza en su cauce hacia el mar, musita palabras y canta:
Mueves tus largos miembros
hacia el mar que te aguarda, musitando palabras
al mar de tu desvelo;
pero tus labios siempre
buscándole la boca,
Río, pero tú siempre
con tu canción de sombra.

Esta sacralización de la naturaleza, así como la correlación con el sujeto poético, evidencia la influencia del Romanticismo, así como de la teoría de la «correspondencia», cuya mayor divulgación se dio a través del conocido soneto de Charles Baudelaire (1821-1867). No obstante, Estancias no es solo un poema exclusivamente sobre la naturaleza, como puede verse en las estancias número once y doce. En estas, el arte es una puerta a lo desconocido, la Música ${ }^{2}$ despierta al Antiguo en el interior del yo:

2 La mención de la música aquí no es casual, pues según George Steiner existe «el reconocimiento recurrente por parte de los poetas, de los maestros del lenguaje, de que la música es el código más profundo, más numinoso, de que el lenguaje, cuando se le capta de verdad, aspira a la condición de música y es llevado por el genio del poeta hasta el umbral de esa condición». En la música, continúa Steiner, «es donde las convenciones estéticas se acercan más al origen de la energía creadora pura, donde más de cerca se tocan sus raíces en el inconsciente y en el centro fáustico de la vida misma» (2006: 60-61). 
11

Tocándolo tan sólo con invisible rayo,

(al desnudo durmiente

bajo signo ignorado)

lo despiertas, oh Música,

para extático alzarlo

al intangible coro

donde es tu imperio exacto.

12

El Antiguo habla en mí.

En mí despierta.

Sus ojos son una agua cineraria.

Un pálido nenúfar, su sonrisa.

El Antiguo creyó saber,

Y su creencia fue sabiduría.

Dobló la cabeza en el amor:

Espuma es hoy blanquísima.

El Antiguo es un ser vago, indefinido, mas podemos establecer algunas características. Por un lado, tiene reminiscencias del mundo natural, como se nota en las referencias a las flores «cineraria»y «nenúfar». Por otro lado, luego de ser alzado al «imperio exacto» de la Música, se encuentra dentro de la voz poética. Aquí, permite la palabra («habla en mí») y consigue sabiduría. No obstante, parece rechazar o negarse al amor cuando dobla su cabeza. La consecuencia de ello es la vuelta a la naturaleza, ya sea la espuma del mar (cuarta estancia) o la espuma de la mañana (octava estancia). En otros términos, si bien se retorna a un elemento positivo como lo es la naturaleza, se sugiere que el amor no pudo ser incluido en esta. 
En cambio, el amor sí está presente, aunque no de manera explícita, cuando se habla de otros seres humanos, como los hijos «Gerardo» $\mathrm{y}$ «Claudio» (decimoctava estancia). Estos renuevan el corazón de la voz poética y hacen que mire con confianza el mundo y diga: «Canta en mí una nueva luz». Parece surgir, entonces, una mirada que resalta en mayor medida lo humano. Como indicador de esto, tenemos fragmentos que ensalzan las necesidades humanas de Sed y Hambre (decimoséptima estrofa), así como el pan y la Amistad (decimonovena estrofa). Y la que consideramos la imagen central del poema revela lo fundamental de la conjunción del amor y lo humano. En esta última estrofa, Sologuren deja de ser solo un «poeta de la naturaleza» y nos muestra que es la universalidad del amor lo que genera la plenitud de la existencia humana:

\author{
Cuerpo a cuerpo \\ Hombre y Mujer, \\ se irán quemando \\ en el fuego blanco \\ del amor. \\ Mano a mano \\ levantarán el árbol \\ de la vida, \\ y sus aires y sus pájaros. \\ Hombre y Mujer, \\ descubrirán que el mundo es compañía \\ y un mismo sol \\ calentará sus huesos, \\ y un mismo anhelo \\ los mantendrá despiertos.
}


Es, en última instancia, el amor humano, representado de manera trascendente en arquetipos de Hombre y Mujer, el que erige el árbol y sus pájaros. Es también el amor el que, finalmente, vencerá la soledad. De esta manera, se representa que la unión humana, a través del amor, es la que infunde energía vital a la naturaleza.

\section{Recinto: desenterramiento como renovación artística vital}

A partir de imágenes del trabajo de desentierro de vestigios del pasado (tanto en su versión arqueológica como la correspondiente al huaquero), Recinto presenta una mirada particular del trabajo poético. Con mayor hermetismo que Estancias, este poema se configura a partir de dos partes que se intercalan. Por un lado, se tienen versos en minúsculas sin puntuación; por otro lado, entre paréntesis, fragmentos de diálogos en cursivas, que corresponden a «Schliemann» y a «el huaquero». No parece existir una relación inequívoca entre ambas partes, sino que enriquecen su significado mutuamente, aunque predomina una forma de glosa, en tanto los fragmentos en cursiva parecen desarrollarse con mayor detalle en los versos que les siguen.

Lo primero a lo que accede el lector son dos epígrafes. Ambos hacen referencia a la muerte. Y el poema inicia en un estado de quietud absoluta, la «nada», análogo a la muerte:

no circulaba nada

nada rodado nada oscilado

la muerte cayó de arriba abajo como un puño 
inapelable

se entrañó el aire

la araña quedó al cabo de su hilo seca

la falena recamada el facetado insecto

intacto y muerto

en la segunda sílaba quedó

del cuculí el quebrado canto

No obstante, tanto los epígrafes, como Recinto, no son textos solo acerca del final de la existencia humana como la conocemos. Al contrario, tanto la perspectiva occidental recogida por D.H. Lawrence como la quechua recogida por Francisco de Ávila, en los epígrafes, sugieren la posibilidad de una existencia posterior a la muerte. Y, de manera similar, el final del poema anunciará el movimiento y la vitalidad: «y todo oscilando / rodando / circulando». Entre estos dos polos, tenemos un proceso de desenterramiento y de creación poética que buscará hacerle frente a la muerte: «decididos a extraer de cien mil / hojas secas el poema / ruido o palabra que fuera a quebrantar / la equívoca eternidad de la muerte» (cuarta estrofa).

Retornemos a la primera estrofa. Esta representa la muerte no solo como el fin de una vida (humana o animal) o de un elemento de la naturaleza, como la estrella que ya no crepita. Esta muerte, que se presenta como una parálisis, afecta también conceptos como «espacio y tiempo», así como el «quebrado canto» de una cuculí; es decir, se trata también de un estancamiento del arte. A partir de aquí, el poema se construye como una búsqueda por restituir dinamismo y vivacidad al arte, así como al mundo en general, a través de 
la práctica artística. Por ello, una de las imágenes constantes será el extraer «de cien mil hojas secas el poema». Esta no es una búsqueda angustiosa solo debido a la sequedad de las hojas -sean parte de los árboles o acumulaciones de papeles escritos-, es, asimismo, una búsqueda por el estado inicial de estas, como se indica cerca del final de la primera estrofa: «nada nadie / ni rey ciudadano o mendigo / entre cien mil hojas secas». En otras palabras, en Recinto, la nada y la soledad serán vencidas a partir de un poema.

Esta esperanza de vencer la parálisis mortífera se muestra en el primer fragmento en cursiva, en que la mosca muestra un camino que escapa de la muerte a través de una existencia incorpórea. En la estrofa que sigue, la «botella subterránea» representa la posibilidad de rescatar un objeto inmóvil y olvidado. Luego de otro fragmento en cursivas que nos describe el trabajo de cavar en la tierra, se nos anuncia una búsqueda semejante al «intentando sin embargo extraer / de cien mil hojas secas el poema». Ahora se intenta "poner la antigua joya sobre el pecho / el joven pecho de Sophia Engastromenos». El objeto arqueológico simboliza un elemento inmóvil y, en ese sentido, «muerto». Sin embargo, logra una vuelta a la «vida» al ponerse en contacto con el presente, el «joven pecho». En otros términos, el pasado, antes seco como las «cien mil hojas», encuentra un nuevo valor al perdurar a través de ser portado por el presente.

Es crucial hacer notar que la joya no es un fin en sí mismo, pues no se le conserva en un pedestal (estaríamos, nuevamente, en el ámbito de lo estático). Al 
contrario, la joya sirve para embellecer a la mujer del presente. Este personaje femenino responde al nombre de la esposa del arqueólogo clásico Heinrich Schliemann (uno de los excavadores en el poema). Y este detalle enriquece la interpretación: el excavador mencionado fue quien encontró el denominado «tesoro de Príamo» o «tesoro de Troya». Y una de las fotografías que perduran de dicho suceso es la que muestra a Sophia Schliemann ${ }^{3}$ luciendo las «joyas de Helena». Entonces, la voz poética muestra un ejemplo modélico de cómo el rescate del pasado puede embellecer el presente.

Avanzando la lectura del poema, se descubre en qué consiste el tesoro que mencionan el huaquero y Schliemann en su tercer diálogo. Como ya referimos, se trata de una victoria frente a la «eternidad de la muerte». En la metáfora de la excavación, los bienes no son solamente las joyas que se encuentra, sino que también luego de romper «la entraña» de la tierra, se descubre «la remota semilla». Se retorna, así, a la centralidad de la naturaleza en la poesía de Sologuren. Esta posibilidad de vitalidad es una semilla que, al arder, genera, como anota el último verso de la cuarta estrofa: «a luz [que] fue el aire de la vida».

Frente a esta iluminación, la voz poética no se extasía ni inicia una etapa de celebración, pues ha sido solo un fugaz vistazo de lo añorado. Luego del acercamiento a aquella «semilla» que genera vida, el enunciador se siente alejado de ella. Por ello, comienza una reflexión sobre por qué su accionar fue vehemente. En el cuarto fragmento del diálogo

3 «Engastromenos» fue su apellido de soltera. 
de Schliemann y el huaquero, parece haber un sentimiento de culpa por «apuñalar» la tierra. Más adelante, la excitación y el apuro por encontrar el tesoro son puestos en tela de juicio. Esto se sintetiza en el quinto fragmento en cursivas, cuando el huaquero y Schliemann parecen pecar de hybris al desear en exceso las riquezas encontradas.

Para volver a aprehender el tesoro, la voz poética busca entender qué medios son requeridos para cumplir su anhelada misión, y descarta diversos elementos que parecerían ser idóneos. Por ejemplo, se menciona que «no basta el fuego / incorruptible del corazón» y «no basta la tierra / cuya sustancia nutrimos / cuya sustancia nos nutre». De este modo, se excluye la naturaleza, antes mostrada como el lugar en que se encontró el tesoro, y la interioridad humana, mostrada a partir del deseo pasional del corazón.

La pregunta que surge entonces es ¿qué sí basta?; pero antes de sugerir alguna respuesta, la voz poética inicia otra meditación, esta vez en torno al amor:

\author{
a nuestro amor no basta \\ menos aún los pobres dioses \\ que día a día levantamos \\ día a día quebramos \\ con manos o palabras \\ no basta \\ nada basta al amor \\ el crudelísmo insaciable
}

En este caso, el amor no puede darse por lo monótono del vivir, como se resalta por la repetición de «día a 
día». Es tanta la exigencia del amor que se transforma en un elemento indeseable, al no poder ser saciado de ninguna manera. Como apunta Eduardo Chirinos en su agudo estudio de Recinto: «la insaciabilidad de ese amor equivale al reconocimiento de la frustración del hablante frente a lo indecible que lo asedia; pero esa frustración, lejos de acallarlo, se convierte en su más ferviente razón de ser» (2015: 64).

Desde este punto, el intenso final del poema revela la verdadera esencia de la riqueza subterránea, así como los medios para encontrarla. Se trata de una poética totalizante, pues supone una síntesis de lo humano y la naturaleza, a través de la imagen del retorno al polvo (último diálogo de Schliemann y el huaquero), según anuncia también la sentencia bíblica. Ahora, ya no se trata de entender lo humano o lo natural por separado, sino de unirlos. Y el efecto enumerativo del desenlace del poema genera el efecto de un conjunto con límites borrosos. Por un lado, el principio vital, el «origen», se manifiesta en una secuencia que requiere dejar de lado el principio aristotélico de no contradicción, dado que categorías que parecerían contradictorias como muerte y vida se unen: «el crujiente muerto y vivo / hacinamiento de las hojas». Asimismo, la diversidad de los entes mencionados no parece responder a una unidad mimética clásica. Por otro lado, no se trata solamente de sugerir la eminencia de la naturaleza, sino que también objetos como una «sandalia»o «la llave colgada de cualquier llavero» se unen a este «origen». Incluso, la experiencia de la ciudad moderna se deja ver en «la prieta bulla de la calle», «la vuelta de 
la esquina» o en la mención del «cine». Sin embargo, consideramos que lo fundamental está en la vuelta del canto, pues se relaciona con el querer extraer un poema de «cien mil hojas secas», deseo repetido a lo largo del poema. Ahora, el canto surge incluso de las piedras, tanto «rodado» (fluido) como «edificado». El canto ya no se corta en su segunda sílaba, ahora surgen «las palabras que son vocablos / que son voces».

Los últimos seis versos del poema nos dan la clave final. Descubrimos que el arte, específicamente la poesía, es también un elemento fundamental para que el movimiento retorne:

las cien mil hojas secas
y al estar decidido
a extraer de ellas el poema
y todo oscilando
rodando
circulando

La plenitud que supone la vuelta al movimiento en el desenlace de Recinto no es solamente una narración de lo que ocurrió en el pasado, sino que es el poema mismo el que ha logrado generar la oscilación final:

la totalidad rescatada cobra movimiento y asistimos a un proceso en el cual todo -la historia, el pasado personal, la naturaleza, las cosas, la tradición literariaregresa de la muerte por el mismo sumidero por donde se fue: la tina vuelve a llenarse de agua «derivando los barcos de papel» y todo aquello que estaba detenido por la muerte vuelve a oscilar, a rodar, a circular. El poema, pues, ha cumplido su objetivo. (Chirinos 2015: 64) 


\section{Esperanza frente a la muerte en La hora}

Este poema se estructura como un relato literario sobre diversas perspectivas que tuvo el enunciador respecto a la poesía. Aunque debemos suponer que se tiene como base las experiencias personales del poeta Sologuren, se trata de una aventura universal de búsqueda de la poesía a la luz de experiencias pasadas.

El poema inicia con la intranquilidad que el pasado le produce a la voz poética. Las «palabras y sucesos [que] desuellan la conciencia» son los que provocan la aventura que, como se verá, no seguirá necesariamente un desarrollo lineal, y será, por tanto, una aventura que deflagra, que arde súbitamente, en diversos puntos. La aventura inicia con la imagen de un barco que se debate entre dos polos: el desorden ya calmado («vórtice devuelto a la quietud y a la calma») y la celebración del desorden («vivo irrefrenablemente en su locura»). Esta antítesis crea «[...] una mortal riqueza / con los azogados planos / del agua». Y el agua, corrupta, genera un primer fracaso: «naufragan los mensajes». En esta situación, «el no abatido pero golpeado entendimiento» surge como la posibilidad de salvación, pues se acerca a una primera figura del arte, la alegoría, y se considera el mar, que antes provocó el naufragio, ya no como lugar de deterioro, sino como el destino que producirá la escritura.

La hora continúa y nos muestra el deseo que generó el entendimiento y la alegoría en la voz poética: «quise leer los afilados signos / del grande del único alfabeto / acotar su infinito». El enunciador, entonces, quiere aprehender el infinito que genera 
el alfabeto e ingresar a una nueva realidad, antes negada, en la figura de un nudo. Esta intención no es solamente un intento metafísico o espiritual, sino que es consciente de la materialidad y funcionalidad del cuerpo: se celebran las funciones cerebrales. $Y$, siendo consciente tanto del infinito del alfabeto como de la finitud del cuerpo, «el rol de la palabra inició su periplo». Este comienzo, no obstante, consiste solo en una permutación de palabras («y si la flor...») que refieren a la naturaleza que, además, se cierra con una fórmula litúrgica en latín. El primer intento poético no trasciende del juego de palabras. La voz poética, conocedora de débil intento, siente que «se adelgaza la flámula», el impulso que inició la aventura de la palabra, pero, a pesar de estar «en el borde del abismo», se mantiene una vitalidad, un aleteo.

En las estrofas novena y décima, la voz poética reflexiona sobre el origen de su actividad artística. Sabe bien que no podrá pulverizar por completo la tradición artística, pues siempre será el origen («el pedestal de mármol cuyo / desnudo remate aún ostenta / el huevo singular / los coloides del origen»). Por otro lado, en la siguiente estrofa, la voz poética también reconoce que tendrá que lidiar con otra tensión: frente a dos daimon, el toro y el león, contrarios y, al mismo tiempo complementarios («ambos reyes [...] comparten sus dominios»), se deberá desobedecer a uno. La voz poética nos dice: «en verdad no sé a quién desirvo / si a la razón o al sueño». Sin embargo, no se trata necesariamente de una elección excluyente entre razón y sueño, sino que únicamente la mezcla de 
ambos resultará en una creación. El sueño de la razón, según la lección de Goya, cría lo caótico: monstruos; pero la razón del sueño engendra orden: emblemas.

La pregunta por el origen guarda un peligro: la inacción. La nuez, el huevo, la simiente -imágenes que guardan, dentro de sí, lo original- no generan otra cosa sino a sí mismos. A partir de ellos, no se puede generar un nuevo origen, sino que «son los espectros sucesivos», son solo una primera chispa que se falsea porque es oscura: un lóbrego relámpago. Esta perspectiva negativa continúa en la decimotercera estrofa, en que la ciudad se nos presenta a través de una enumeración de ocupaciones. Se menciona tanto a burócratas y dignatarios del poder político, como a técnicos, parturientas y contadores de sílabas. Sin embargo, esta enumeración no deviene en una celebración de la comunidad universal como en Walt Whitman ${ }^{4}$, sino que es un recuento de la incompletitud y el fracaso humanos: «pequeña muestra son de una plural falacia». Si bien son criaturas «[...] tocadas por la húmeda / tiniebla maternal de la especie», al igual que el lóbrego relámpago, carecen de plenitud. La igualdad entre todo (tú, yo, el león, el toro, el sol solitario, el mar solo) se da en la expectativa o búsqueda de la plenitud, del «relámpago divino». Y, a partir de esta certeza de futura plenitud, la voz poética declara la interrelación de todo el cosmos. No se trata solamente de una mirada panteísta, sino que también incorpora elementos no naturales como los guarismos, el triángulo y la esfera, conceptos propios de las ciencias matemáticas. Y mediante

\footnotetext{
4 En el poema «The pure contralto sings in the organ loft...» de Song to myself.
} 
tres versos que recuerdan la poética de César Vallejo, la voz poética se reconoce en la injusticia: «y lo que no es nuestro / pero debía serlo / también tu semejante».

Hasta aquí, se tiene la primera parte del viaje. Iniciado por el recuerdo, e intensificado a través del entendimiento y las ansias por acotar el infinito del alfabeto, el «periplo de la palabra» llega a un primer puerto. Esta primera aventura implica el reconocimiento de lo que podría reconocerse como una tradición artística -el origen, ese primer pedestal de mármol- que si bien siempre es el origen, debe renovarse, pues por sí mismo no puede dar lugar a nada. Se necesitará el sueño de la razón o la razón del sueño para tentar el «relámpago divino».

En la estrofa decimoséptima, la voz poética reinicia su aventura poética, luego del agotamiento del fruto: «no ofrece ya la fragancia [...] / solo su dura piel de inútil desecho». A pesar de un primer signo de vejez o dificultad que se anuncia con el bastón, se vuelve al canto, aunque sea tenue. Esta nueva aventura no significará una destrucción del pasado, sino que se retoman los orígenes tanto artísticos como familiares. Antes de iniciar un nuevo viaje, se debe poner en perspectiva el pasado: «[...] la furtiva luz / de las imágenes primeras / de la mesa ruidosa de pan abastecida / de tanto amor de tanto / presente humano y familiar / se vuelve con los recuerdos enzarzados». Al igual que al inicio del poema, nuevamente una memoria parece incomodar a la voz poética. Aquellos recuerdos enzarzados la obligan no solo a un nuevo inicio, sino también a un balance de lo realizado hasta el momento. La 
voz poética siente que ha dejado de lado el mar, que se había vuelto el destino en la tercera estrofa; pero, por otro lado, mantiene tanto el camino dificultoso de la creación poética («la sal de las lágrimas») como el fulgor de la última brasa.

La lección más importante de este viaje es la trascendencia del arte en una tradición: «en tanto haya / una canción / y una voz que la recuerde / en tanto que haya / una voz / y una canción que la recuerde / estaré vivo». La vitalidad del arte depende de un doble proceso. Una canción subsiste si otra voz -también capaz de cantar- la recuerda. Y, al mismo tiempo, la voz solo mantendrá su vitalidad si una canción la recuerda. Así como el pedestal de mármol subsiste porque la inevitable pregunta por el origen obliga a mirarlo, las canciones y las voces podrán mantenerse vivas si otras canciones o voces retornan a ellas. Cabe mencionar que esta subsistencia en la tradición no debe entenderse como una parálisis. Al contrario, como se dice en la estrofa que sigue: «las navegaciones reverdecieron mis años». Así como otras canciones o voces pueden mantenernos con vida, al mismo tiempo, la búsqueda también nos mantiene vitales. Y la búsqueda, en el ámbito de la poesía, es la misma práctica poética: no vivir de recuerdos o famas pasadas, sino continuar con la alquimia del verbo.

Lamentablemente, este optimismo de mantenerse vivo choca con la violencia del tiempo y posterga el goce: «el pan que hiere por su falta / el niño que ya es un hombre vencido / la especie que asesina su futuro / diariamente me dicen hasta cuándo / el gozo será entre 
tanto un olvido». Si antes ya se nos había mostrado la posibilidad de una humanidad no plena en los habitantes de la ciudad, ahora se nos muestra que estos no son dueños de lo que les corresponde, impidiendo la plenitud de la voz poética. Así, esta también se siente ligada al destino de los demás, ya que, como enunció estrofas atrás, todos están unidos por la espera del «relámpago divino». Todos estos seres podrían hacer suyo el último verso de la vigesimotercera estrofa: «sin embargo no entierro mi esperanza». Esta manera de mirar el futuro no debe verse como optimismo en el progreso material, sino que recuerda también la esperanza vallejiana en la redención en el amor universal. $Y$, precisamente, en la siguiente estrofa encontramos un pequeño himno al amor que, junto a la esperanza, revitalizan la voz poética. A la luz de este nuevo ímpetu, se mira, nuevamente, el pasado. La voz poética reflexiona sobre su formación: cómo, a pesar de ser un pájaro espantado con las plumas emplomadas, fueron posibles un «cálido canto» y una búsqueda en los «calidoscópicos cielos».

A partir de la vigesimoséptima estrofa, La hora sintetiza el viaje poético realizado. Síntesis que, además, es un nuevo viaje: la obra "después antes o siempre [...] nos perturba». No podemos desligarnos de ella, siempre volveremos al origen, pero esto no elimina la posibilidad de que una flor nos lleve «más allá». La voz poética dice «las estaciones se desplazan por mis venas / acaricio sin tregua el rostro natural». Este sentir panteísta motiva la búsqueda, que nos lleva a la plenitud. Como ejemplo, la voz poética relata un hecho biográfico 
de la vida de Sologuren: el descubrimiento del haiku le permitió explorar una nueva manera de ver la naturaleza. Este descubrimiento, no obstante, no invalida las experiencias anteriores: «la historia no se vacía de sucesos». La experiencia vital y, por extensión, el arte es, entonces, un enriquecimiento constante.

Sin embargo, nuevamente, cuando parece alcanzarse una máxima plenitud a través del arte, la violencia del mundo vuelve a desestabilizar:
asistimos a una apoteósica danza de la muerte
al espectáculo del siglo
con comparsas masivas
y coreografías de inenarrable pesadilla
con nubes de cercenado esplendor
pero eficazmente radiactivas
los megatones miden
sus méritos artísticos.

El dolor ante la violencia que «jamás ha sembrado [...] / tantos cuerpos bajo el sol» es como un clavo que afecta no solo el corazón, sino también el cerebro. No se trata únicamente de una sensibilidad ante el dolor, es, asimismo, un problema para el entendimiento. Se trata, en definitiva, del absurdo de la violencia de nuestra época. Existe una duda sobre el hombre: si podrá, como un fénix, erigirse nuevamente «[...] sobre esta carroña inmensa». Aunque exista una voz artística viva, como Vincent van Gogh, que afirme que la miseria jamás acabará, la voz poética termina el poema «pero repito / sin embargo, no entierro la esperanza». Esperanza que dará comienzo a un nuevo viaje, aunque, esta vez, ya fuera del poema La hora. 


\section{Bibliografía}

CHIRINOS, Eduardo. «Una lectura de «Recinto» de Javier Sologuren», en Cuadernos hispanoamericanos. № 778. Madrid, 2015, págs. 54-68.

SILVA-SANTISTEBAN, Ricardo. «El universo poético de José María Eguren», en Poesías completas de José María Eguren. Lima, Academia Peruana de la Lengua y Biblioteca Abraham Valdelomar, 2015, págs. 7-122.

SOLOGUREN, Javier. Hojas de herbolario. Tomo X de las Obras completas de Javier Sologuren. Lima, Pontificia Universidad Católica del Perú, 2005.

- Vida continua. Obra poética. Tomo I de las Obras completas de Javier Sologuren. Lima, Pontificia Universidad Católica del Perú, 2004.

STEINER, George. «El silencio y el poeta», en Lenguaje y silencio. Sevilla, Gedisa editorial, 2006, págs. 53-72. 